\title{
Facing unpalatable truths: part 1
}

It is an unpalatable truth that $6 \%$ of young people with a diagnosis of psychosis kill themselves. ${ }^{1}$ They do so early on in the course of the illness perhaps because they realise the line between 'them' and 'us' has blurred and the label of serious mental illness has not so much become sticky as stuck. The diagnosis and treatment often herald an increased risk of physical health problems and social exclusion through unemployment, poverty, and discrimination.

It is an unpalatable truth that teenage depression is on the increase. ${ }^{2}$ When a teenager sobs quietly to themselves in a state of 3 am sleeplessness, can't eat, can't concentrate, and wonders if life will ever get any better, the best most of us can offer to those in real distress is a CAMHS waiting list. The drugs we can prescribe are limited and have significant side effects, and teenagers can be hard to engage with talking therapies, sometimes because they are not delivered in a youthsensitive manner. The 'lucky' families can pay to leapfrog the waiting list but too many of those young people become the unhappy young adults we see with recurrent depression.

It is an unpalatable truth that occasionally we are part of the problem. Not so long ago I ran a focus group with people with serious mental illness and local GPs to discuss how we could, together, improve services. As I sat eating sandwiches with three or four service users, a GP arrived, looked round the room and said, 'Oh, I see I'm the first person here.' It was a small slip that gave a tiny glimpse of living with mental illness. A paper in the BMJ this year ${ }^{3}$ found that patients really rather like their GP formally asking about their symptoms of depression, but those same depression indicators remain professionally contentious, creating antipathy rarely seen in other areas of primary care clinical practice. $^{4}$

How do we begin to change this? How can a GP alter societal attitudes, sort out employment issues, minimise drug side- effects? The unpalatable truth is we can't. But we can look at how welcoming our own surgeries are for young people in general and those in distress in particular. We can use our practice-based commissioning levers to develop the services we need. We can reflect on our own views of mental health and illness. We can make a small start.

\section{Helen Lester}

\section{REFERENCES}

1. Palmer B, Pankratz S, Bostwick J. The lifetime risk of suicide in schizophrenia: a re-examination. Arch Gen Psychiatry 2005; 62(3): 247-253.

2. National Collaborating Centre for Mental Health (NCCMH). Depression in children and young people: identification and management in primary, community and secondary care. London: NICE, 2005. http://www.nice.org.uk/CG28 (accessed 8 May 2009).

3. Dowrick C, Leydon G, McBride A, et al. Patients' and doctors' views on depression severity questionnaires incentivised in UK quality and outcomes framework: qualitative study. BMJ 2009; 338: b663.

4. Campbell S, McDonald R, Lester HE. The experience of pay for performance in English family practice: a qualitative study. Ann Fam Med 2008; 6(3): 228-234.

DOI: 10.3399/bjgp09X453387 